\title{
The Assessment and Prediction of Prospective Memory after Stroke
}

\author{
Christy $\operatorname{Hogan}^{1,2}$ (D) , Petrea Cornwell ${ }^{3,4}$ (D) , Jennifer Fleming ${ }^{2}$ (D) and David H. K. Shum ${ }^{5,6, *}$ (D) \\ ${ }^{1}$ School of Applied Psychology, Griffith University, Mt Gravatt \\ ${ }^{2}$ School of Health and Rehabilitation Sciences, University of Queensland \\ ${ }^{3}$ School of Allied Health Sciences, Menzies Health Institute Queensland, Griffith University \\ ${ }^{4}$ The Prince Charles Hospital Metro North Hospital and Health Service \\ ${ }^{5}$ Department of Rehabilitation Sciences, The Hong Kong Polytechnic University \\ ${ }^{6}$ School of Applied Psychology, Griffith University, Gold Coast
}

(Received October 9, 2019; Final Revision March 1, 2020; Accepted March 3, 2020; First Published Online June 12, 2020)

\begin{abstract}
Objective: Prospective memory (PM) is the memory used when intentions are to be carried out in the future. Little research has been conducted examining PM after stroke. This study aimed to determine if PM is impaired after stroke through comparison of individuals with stroke to healthy controls. Additionally, it aimed to explore the predictors of PM performance post-stroke. Method: Twenty-eight individuals with stroke and 27 neurologically healthy controls completed the Cambridge Prospective Memory Test (CAMPROMPT), 2 self-report PM questionnaires, and multiple cognitive measures. Results: Individuals with stroke performed significantly lower on both event- and time-based PM than controls on the CAMPROMPT, indicating PM impairment. Event-based PM after stroke was significantly predicted by age, retrospective memory (RM), and global cognitive function, whereas time-based PM was only predicted by the metacognitive skill of note-taking. Age and note-taking predicted time-based PM for controls, whereas only age predicted event-based PM for control participants. Conclusions: The findings of this study have helped to confirm that PM impairment does exist after stroke, particularly when using a standardised PM measure. Furthermore, PM impairment may be predicted by variables, such as age, strategy use, RM, and cognitive ability.
\end{abstract}

Keywords: Humans, Memory, Intention, Cognition, Stroke, Surveys and Questionnaires

Prospective memory (PM) is the encoding, storage, and delayed retrieval and execution of intended actions (Shum, Levin, \& Chan, 2011), with two main types: time- and event-based (Kvavilashvili \& Ellis, 1996). Time-based PM requires an action to be completed at a certain time or after a certain amount of time, whereas event-based PM requires an action to be completed when a specific event occurs. It is generally understood that the two types of PM rely on different monitoring strategies and require differing levels of cognitive capacity (Einstein \& McDaniel, 1990). The multi-process framework (McDaniel \& Einstein, 2000) suggests that PM performance requires either strategic monitoring for a PM cue or automatic spontaneous retrieval, while the preparatory attention and memory model (Smith, 2003) suggests that PM performance is always reliant on monitoring for a PM cue including event-based tasks. Therefore, the cognitive demand and difficulty for each PM task is dependent on the monitoring approach used by the individual and the ease of detection of the PM cue (e.g., its salience, focality).

*Correspondence and reprint requests to: Prof. David H. K. Shum, Faculty of Health and Social Sciences, The Hong Kong Polytechnic University, Hung Hom, Kowloon, Hong Kong. E-mail: david.shum@polyu.edu.hk
The prefrontal lobes (particularly BA10) are activated during PM tasks (Burgess, Gonen-Yaacovi, \& Volle, 2011). Everyday functioning is heavily reliant on PM abilities, and impairments in either type can influence one's ability to independently perform activities of daily living (Man, Yip, Lee, Fleming, \& Shum, 2015). Changes in cognitive ability commonly occur after stroke (Andrews, Halford, Chappell, Maujean, \& Shum, 2014). Impairments in memory function are frequently reported by individuals with stroke and their families; however, the previous literature has focused more on retrospective memory (RM; memory for information from the past) rather than PM (Andrews, Halford, Shum et al., 2014). Previous research investigating the impact of stroke on PM performance shows varied results depending on the type of measure used. Studies utilising behavioural measures have generally found that PM impairment occurs after stroke, especially for time-based PM (Hogan, Fleming, Cornwell, \& Shum, 2016). One study (Kim, Craik, Luo, \& Ween, 2009) found no difference in event-based PM performance but significantly poorer time-based PM for individuals with stroke $(n=12)$ when compared to controls $(n=12)$. An intervention study (Miller \& Radford, 2014) reported that individuals 
with stroke $(n=27)$ performed lower than normative means on the Royal Prince Alfred PM Test at baseline. Another intervention study (Mitrovic, Matthews, Ohlsson, Holland, \& McKinlay, 2006) similarly reported that onethird of their stroke sample $(n=15)$ showed PM impairment at baseline according to the normative data of the Cambridge Prospective Memory Test (CAMPROMPT). Utilising the CAMPROMPT, two studies (Barr, 2011; Man, Chan, \& Yip, 2015) found that individuals with stroke $(n=22$, $n=40$, respectively) performed significantly poorer than controls ( $n=22, n=44$, respectively) on PM, particularly for time-based PM. The previous research is limited by small sample sizes, inconsistency in PM assessments used, and the majority have not explored reasons for PM impairment after stroke.

\section{Predictive Factors for PM Impairment}

PM relies on a number of interacting cognitive processes, including planning, cognitive flexibility, disruption of an ongoing activity, and initiation of an action (Shum, Fleming, $\&$ Neulinger, 2002). While the factors involved are often difficult to isolate, it is generally understood that executive functions (EFs) play an important role (Otani et al., 1997). In healthy adults, EFs (including planning, monitoring, inhibition, and cognitive flexibility) can predict PM performance, even after controlling for other factors (i.e., education; Martin, Kliegel, \& McDaniel, 2003). Furthermore, individual differences in EF can predict PM, particularly in old age, with high levels of PM performance in older adults dependent on better EF abilities. Seventy-one percent of Australians who have had a stroke are aged over 65 years (Australian Institute of Health and Welfare [AIHW], 2016). Therefore, it is reasonable to assume that age may play a role in PM in individuals with stroke, if not directly, then through age-related cognitive decline. Previous research reports that EFs are more predictive of timethan event-based tasks, suggesting increased self-monitoring involved in time-based PM places higher demand on executive processes (Groot, Wilson, Evans, \& Watson, 2002). However, other research has found EF, specifically shifting and inhibition, predicts event-based PM performance tasks as well (Schnitzspahn, Stahl, Zeintl, Kaller, \& Kliegel, 2013; Zuber, Kliegel, \& Ihle, 2016).

Preliminary findings suggest that processing speed, attention, EF, and RM significantly predict time-based PM after stroke, whereas only RM predicts event-based PM after stroke (Kant et al., 2014). These findings highlight that timebased PM is more complex than event-based PM, requiring more cognitive processes (i.e., time monitoring), evidenced by the finding that participants who checked the clock more performed better on time-based PM. Additionally, individuals with stroke checked the time less than controls, leading to poorer time-based PM performance.

Age has been found to negatively impact PM performance, particularly time-based PM (Einstein, McDaniel, Richardson, Guynn, \& Cunfer, 1995; Kvavilashvili, Kornbrot, Mash, Cockburn, \& Milne, 2009). The age by type of task interaction proposes that tasks requiring higher degrees of self-initiation show larger age-related performance reductions. Therefore, older adults perform worse on tasks requiring high levels of self-initiation. While previous literature generally agrees that time-based PM is impacted negatively by age, not all research has found this pattern. Some fail to find any age-related declines in time-based PM (Niedźwieńska \& Barzykowski, 2012; Rendell \& Craik, 2000), whereas others (d'Ydewalle, Luwel, \& Brunfaut, 1999) find older adults perform better on time-based tasks. The impact age has on event-based PM is also mixed. While some studies outline age effects on event-based PM (Kvavilashvili et al., 2009; Park, Hertzog, Kidder, Morrell, \& Mayhorn, 1997), a similar number report no such effect (Einstein \& McDaniel, 1990; Einstein et al., 1995; Henry, MacLeod, Phillips, \& Crawford, 2004), possibly due to the variability in measures used. A meta-analysis concluded that age-related deficits exist for both time- and event-based PM when tested in the laboratory, but when using naturalistic PM tasks, older participants (groups with $M$ age $>55$ years and $\geq 15$ years older than younger groups) perform better than younger participants ( $M$ age range $=18-59$; Henry et al., 2004).

Metacognition is defined as the higher order thinking involved in overseeing and regulating cognitive processes (Livingston, 2003). Major components of metacognition include self-awareness, self-regulation, and self-monitoring (Al Banna, Redha, Abdulla, Nair, \& Donnellan, 2016). The ability to remember effectively in everyday life is dependent on metacognitive factors, including the ability to monitor ongoing performance, predict what amount of information can be remembered, and knowing when to use memory aids (Knight, Harnett, \& Titov, 2005). Self-awareness impairments are common following neurological injury (Leung \& Liu, 2011). Previous literature suggests that self-reported PM after stroke be interpreted with caution, as impairments in self-awareness are highly probable and participants may report their pre-, rather than post-stroke abilities (Brooks, Rose, Potter, Jayawardena, \& Morling, 2004; Kim et al., 2009; Man, Yip, et al., 2015). Mixed results have been found when examining the relationships between self-report and behavioural measures of PM, with one study reporting significant positive correlations between the CAMPROMPT total and both the total and retrospective subscale of the Prospective and Retrospective Memory Questionnaire (PRMQ; Crawford, Henry, Ward, \& Blake, 2006) but not for the prospective subscale (Barr, 2011). Another study (Man, Fleming, Hohaus, \& Shum, 2011) reported that traumatic brain injury (TBI) patients' responses on the Brief Assessment of PM (BAPM) did not significantly correlate with patient scores on the CAMPROMPT and concluded that results reflected a lack of validity for self-reported PM questionnaires compared to laboratory-based tasks (Uttl \& Kibreab, 2011). It is important to evaluate whether selfreported PM predicts PM performance after stroke, to determine if deficits in self-awareness of PM could be a reason for PM impairment, for example, as a result of failure to use strategies. 
Table 1. Demographic information for individuals with stroke and neurologically healthy controls

\begin{tabular}{|c|c|c|c|c|c|c|c|}
\hline \multirow[b]{2}{*}{ Variable } & \multicolumn{2}{|c|}{ Stroke $(n=28)$} & \multicolumn{2}{|c|}{ Control $(n=27)$} & \multirow[b]{2}{*}{$t$} & \multirow[b]{2}{*}{$d f$} & \multirow[b]{2}{*}{$p$} \\
\hline & $M$ & $S D$ & $M$ & $S D$ & & & \\
\hline Age (years) & 62.86 & 13.05 & 56.41 & 10.69 & 2.00 & 53 & .051 \\
\hline Education (years) & 14.09 & 4.77 & 14.26 & 4.77 & -.15 & 48.28 & .878 \\
\hline Premorbid IQ & 103.75 & 12.94 & 105.37 & 11.34 & -.49 & 53 & .624 \\
\hline Line bisection & 15.64 & 2.25 & 16.44 & .93 & -1.72 & 53 & .092 \\
\hline \multicolumn{8}{|l|}{ DASS-21 } \\
\hline Depression & 4.00 & 4.07 & 2.89 & 3.70 & 1.06 & 53 & .295 \\
\hline Anxiety & 2.86 & 2.97 & 2.22 & 2.52 & .86 & 53 & .397 \\
\hline Stress & 5.57 & 4.75 & 4.67 & 3.39 & .81 & 53 & .421 \\
\hline
\end{tabular}

Note. $* p<.05, * * p<.01$. DASS-21 = Depression, Anxiety, and Stress Scale-21.

\section{Aims and Hypotheses}

In order to clarify the extent of PM impairment after stroke, this study aimed to compare the PM performance of individuals with stroke to healthy controls using a standardised clinical measure (viz., CAMPROMPT). It was hypothesised that individuals with stroke would perform more poorly on the CAMPROMPT when compared to controls, particularly on time-based PM. Very little is known about why PM impairment occurs after stroke and only one study has examined possible predictors (i.e., cognitive functions) of PM performance after stroke (Kant et al., 2014). Therefore, the current study utilised a multifaceted approach to clarify the nature of PM impairment after stroke. The current study examined whether demographic, cognitive, and metacognitive factors predict PM performance and explored possible causes of PM impairment post-stroke. It was hypothesised that demographic, cognitive, and metacognitive factors would significantly predict PM performance after stroke.

\section{METHOD}

\section{Participants}

Twenty-eight individuals with stroke ( 17 females; age ranged between 34 and 83 years old) were recruited through multiple health facilities and stroke organisations in South-East Queensland, Australia. Participants were required to be aged 18-85 years, with a diagnosis of cerebrovascular accident within the last 5 years (individuals with transient ischaemic attack not included), and living in the community post-stroke for at least 1 month. Participants were excluded if their stroke was located in the brainstem/cerebellum; had a history of previous brain injury/neurological illness; diagnosis of dementia/neurodegenerative illness; significant psychiatric disorder; insufficient communicative ability (i.e., severe aphasia); significant visual, hearing, or hand function impairment that would impact their ability to participate; or current alcohol/substance abuse.

Time since stroke ranged from 2 to 53 months $(M=16.13$, $S D=13.82$ ) and individuals had been living in the community between 1 and 52 months post-stroke $(M=14.80, S D=12.93)$.
The type of stroke included 19 ischaemic, 7 haemorrhagic, and 2 with both, with 11 left hemisphere, 11 right, 5 bilateral, and 1 unknown lateralisation (18 first-time stroke). Stroke location and type were identified by medical records (including neurological findings) where available. Eight individuals had no significant disability; 11 slight; 7 moderate; and 2 moderately severe disability (Modified Rankin Scale; Rankin, 1957). Participants reported high levels of daily functioning $(M=52.68, S D=14.37$; Nottingham Extended Activities of Daily Living Scale; Nouri \& Lincoln, 1987) completing tasks independently or independently with difficulty.

Twenty-seven neurologically healthy controls (20 females; age ranged between 44 and 79 years old) were recruited through Griffith University (subject-pool, Learning Space, research volunteer email) and community groups. Participants were required to be aged 18-85 years, with no history of neurological illness, brain injury, or stroke. Participants with significant psychiatric illness, current alcohol/substance abuse, significant visual/hearing impairment, or insufficient communicative ability were excluded. The individuals with stroke and controls did not differ significantly on any demographic variable, line bisection (visual test), or level of depression, anxiety, or stress (Depression, Anxiety, and Stress Scale-21; Henry \& Crawford, 2005; all $p>.05$, Table 1).

\section{Measures}

\section{Prospective memory}

The CAMPROMPT (Wilson et al., 2005) is a standardised objective measure of PM, featuring six PM tasks (three time-based and three event-based) embedded throughout/at the end of an ongoing task (paper and pen puzzles/quizzes). Participants are instructed to use any strategy they like to help them remember (i.e., take notes). Four scores are calculated: total PM (0-36), time-based (0-18), event-based (0-18), and RM score (0-10), with larger scores indicating better performance. The RM task was embedded after one of the eventbased PM tasks. At the beginning of the test, five everyday items were hidden around the room and participants were instructed to remind the experimenter at the end of the test that they had hidden the items (event-based PM) and outline 
what the items were and where they were hidden (RM). Participants were given 1 point for each correct item and each item location they recollected. The CAMPROMPT is a valid and reliable measure [inter-rater reliability (.99), test-retest reliability (.64)], has a parallel form, normative data, and has been used in previous stroke research (Man, Chan, et al., 2015).

\section{Cognitive processes}

The Trail Making Test (TMT) measures EF (Tombaugh, 2004). In Part A, individuals are required to connect 25 numbers in ascending order and numbers and letters alternatelty in ascending order (i.e., 1-A-2-B-3-C- etc.) in Part B. Scoring is recorded as the completion time (s), with lower scores indicating better performance, and a maximum score of 300 s (Strauss, Sherman, \& Spreen, 2006). The executive component is isolated by calculating the difference between the two parts (i.e., B-A).

The Hopkins Verbal Learning Test-Revised (HVLT-R; Benedict, Schretlen, Groninger, \& Brandt, 1998) was used to measure participants' RM. Participants are read 12 words, 1 word every $2 \mathrm{~s}$, for 3 trials. Participants are then required to repeat the words back in any order after each trial and after a 20-min delay. Total recall (total words correctly recalled for three trials) and retention (highest of trials 2 or 3 divided by trial 4, multiplied by 100) were calculated for the current study. Reliability coefficients (test-retest) for HVLT-R are within acceptable limits $(r=.55-.78)$, and the task has been used in stroke samples (Andrews, Halford, Shum, et al., 2014).

The Montreal Cognitive Assessment (MoCA Original Version 7.1; Nasreddine et al., 2005) is a brief assessment of global cognitive function, evaluating multiple domains including visuospatial ability, EF, short-term memory recall, attention, concentration, working memory, language, and orientations to time/place. Scores range between 0 and 30, with scores less than 26 indicating mild cognitive impairment (MCI). The MoCA has high test-retest reliability $(r=.92)$, good internal consistency $(\alpha=.83)$, excellent sensitivity in identifying MCI (90\%) and Alzheimer's disease (100\%), and very good to excellent specificity (87\%).

\section{Metacognitive variables}

Strategy use was measured by spontaneous note-taking on the CAMPROMPT as a dichotomous variable (i.e., no notetaking $v s$. note-taking). Self-reported PM was measured by the PRMQ prospective score and BAPM total. The PRMQ (Smith, Del Sala, Logie, \& Maylor, 2000) is a 16-item questionnaire that examines PM and RM failures in everyday life, with higher scores indicating more memory lapses. It has been used in previous stroke populations (Kim et al., 2009) and has good internal consistency (total $=.89, \mathrm{PM}=.84$, $\mathrm{RM}=.80$, respectively; Crawford, Smith, Maylor, Della Sala, \& Logie, 2003). The BAPM 16-item questionnaire assesses frequency of PM failure within the last month, with higher scores indicating more PM lapses. It has good reliability and validity ( $\alpha=.84$; Man et al., 2011) indicating acceptable internal consistency and has been used previously in stroke populations (Man, Yip, et al., 2015).

\section{Procedure}

Ethical clearance was obtained from The Prince Charles Hospital Human Research and Ethics Committee and the Griffith University Ethics Committee. Written consent was obtained from all participants before starting the first session. The current study was conducted as part of a larger study; therefore, a neuropsychological battery was conducted over two sessions, each taking approximately $1.5 \mathrm{hr}$. Sessions were held in the participant's home or in a quiet room at the university. After completion of both sessions, participants were compensated \$20 (AUD), or 2 credit points if recruited through the Griffith subject-pool.

\section{Statistical Analyses}

All data were analysed using IBM SPSS Statistics for Windows (Version 25; IBM Corporation, 2017). The CAMPROMPT RM and HVLT-R retention scores were significantly skewed. Transformations were applied; however, did not change the results, thus untransformed scores are reported. Nonparametric tests were used for skewed data. Two outliers were removed from the CAMPROMPT RM score as they impacted the $t$-test results. Independent samples $t$-tests were used to compare the CAMPROMPT scores between stroke and control groups. Independent $t$-tests were also used to compare the scores on the cognitive (TMT, HVLT-R, and MoCA) and metacognitive measures (BAPM total, PRMQ PM) between the two groups. A chisquare analysis was used to compare the two groups on note-taking on the CAMPROMPT. A $2 \times 2$ [Group (stroke $v s$. control) $\times$ PM Task Type (event- $v s$. time-based)] mixed ANOVA was used to examine the main and interaction effects of the two independent variables on CAMPROMPT performance. Pearson's correlation coefficient examined the relationships between the CAMPROMPT and other variables of interest. Four multiple regression analyses were used to examine demographic, cognitive, and metacognitive predictors of PM (time- and event-based) for individuals with stroke and controls.

\section{RESULTS}

\section{CAMPROMPT and Cognitive and Metacognitive Measures}

Independent samples $t$-tests were conducted comparing individuals with stroke and controls on the CAMPROMPT total, time- and event-based PM, as well as the cognitive measures (TMT, HVLT-R total recall, and MoCA) and metacognitive measures (BAPM total, and PRMQ PM; see Table 2). A chisquare test was used to compare CAMPROMPT note-taking 
Table 2. Comparisons on the CAMPROMPT, cognitive, and metacognitive variables between individuals with stroke and neurologically healthy controls

\begin{tabular}{|c|c|c|c|c|c|c|c|c|}
\hline \multirow[b]{2}{*}{ Variable } & \multicolumn{2}{|c|}{ Stroke $(n=28)$} & \multicolumn{2}{|c|}{ Control $(n=27)$} & \multirow[b]{2}{*}{$t$} & \multirow[b]{2}{*}{$d f$} & \multirow[b]{2}{*}{$p$} & \multirow[b]{2}{*}{$d$} \\
\hline & $M$ & $S D$ & $M$ & $S D$ & & & & \\
\hline CAMPROMPT total PM & 19.00 & 9.54 & 25.19 & 6.10 & -2.88 & 46.15 & $.006^{* *}$ & -.77 \\
\hline CAMPROMPT event-based PM & 9.86 & 4.43 & 13.59 & 3.52 & -3.45 & 53 & $.001 * *$ & -.93 \\
\hline CAMPROMPT time-based PM & 8.79 & 5.34 & 11.59 & 3.68 & -2.28 & 48.08 & $.027 *$ & -.61 \\
\hline CAMPROMPT RM & 9.46 & 1.17 & 9.89 & .42 & \multicolumn{2}{|c|}{$U=282.00$} & .06 & \\
\hline TMT & 89.19 & 57.04 & 43.21 & 27.22 & 3.78 & 37.25 & $.001 * *$ & 1.03 \\
\hline HVLT-R total recall & 19.75 & 5.83 & 23.74 & 3.76 & -3.03 & 46.32 & $.004 * *$ & -.81 \\
\hline HVLT-R retention & 72.15 & 33.85 & 91.26 & 12.50 & \multicolumn{2}{|c|}{$U=260.50$} & $.047 *$ & .55 \\
\hline MoCA total & 25.23 & 2.82 & 26.54 & 2.25 & -1.85 & 50 & .070 & -.51 \\
\hline CAMPROMPT note-taking & Yes $=16$ & No $=12$ & Yes $=21$ & No $=6$ & $\chi^{2}=2.66$ & 1 & .103 & \\
\hline BAPM total & 1.60 & .46 & 1.37 & .32 & 2.08 & 48.26 & $.043^{*}$ & .58 \\
\hline PRMQ PM & 21.32 & 6.92 & 18.15 & 4.50 & 2.02 & 46.55 & $.049 *$ & .54 \\
\hline
\end{tabular}

Note. $* p<.05, * * p<.01$. CAMPROMPT $=$ Cambridge Prospective Memory Test; $\mathrm{PM}=$ prospective memory; $\mathrm{RM}=$ retrospective memory; TMT $=$ Trail Making Test; HVLT-R = Hopkins Verbal Learning Test - Revised; MoCA = Montreal Cognitive Assessment; BAPM = Brief Assessment of Prospective Memory; PRMQ = Prospective and Retrospective Memory Questionnaire.

Table 3. Clinical category placement based on age, IQ, and CAMPROMPT total PM score

\begin{tabular}{lcc}
\hline \hline Category & $\begin{array}{c}\text { Stroke } \\
(n=28)\end{array}$ & $\begin{array}{c}\text { Control } \\
(n=27)\end{array}$ \\
\hline Impaired/borderline & 8 & 3 \\
Poor/average/above average & 19 & 21 \\
Very good & 1 & 3 \\
\hline \hline
\end{tabular}

Note. CAMPROMPT $=$ Cambridge Prospective Memory Test $\mathrm{PM}=$ prospective memory.

between the groups, and a Mann-Whitney U-test was used to compare HVLT-R retention and CAMPROMPT RM between the groups (see Table 2). CAMPROMPT total, event-, and time-based PM was significantly higher for controls than individuals with stroke (moderate, large, and moderate effect size, respectively) indicating PM impairment after stroke. When placed into clinical categories (i.e., impaired/ borderline, poor/average/above average, and very good) using normative data, there was no significant difference between groups $\left(\chi^{2}=3.36, p=.19\right)$ even though more individuals with stroke fell into the impaired/borderline range than the controls (Table 3). No significant differences in CAMPROMPT RM scores were found between the control and stroke groups, possibly due to ceiling effects. Controls performed significantly better on the TMT (large effect size) and HVLT-R (recall and retention) compared to individuals with stroke (large and moderate effect size, respectively). No significant differences were found between the groups for CAMPROMPT note-taking. Individuals with stroke selfreported significantly more PM failures than controls on both the BAPM and PRMQ PM (medium effect sizes).

A $2 \times 2$ mixed ANOVA was used to investigate the main and interaction effects of Task Type and Group on CAMPROMPT PM performance. As expected, a significant main effect for Task Type was obtained, $F(1,53)=8.97$, $p=.004, \eta_{p}^{2}=.145$ (medium effect size), with both groups scoring higher on event-based compared to time-based PM. A significant main effect of Group was found, $F(1,53)=9.80, p=.003$, $\eta_{p}{ }^{2}=.156$ (medium effect size), with controls scoring better than individuals with stroke on both event- and time-based PM. No interaction between Task Type and Group was found, $F(1,53)=.82, p=.37, \eta_{p}^{2}=.015$ (small effect size).

\section{Correlational Analyses and Predictor Variables}

Results of correlation analyses are summarised in Table 4. All cognitive and metacognitive variables significantly correlated with both time- and event-based PM for individuals with stroke, with moderate to strong relationships. Age was significantly correlated with event-based PM for individuals with stroke (moderate relationship). Variables entered into the regression analysis for time-based PM for individuals with stroke included: EF measured by the TMT, total recall and retention on the HVLT-R, global cognitive function measured by the MoCA, note-taking on the CAMPROMPT, and self-reported PM (PRMQ PM and BAPM total). All variables including age were entered into the regression analysis for event-based PM for individuals with stroke. Age was significantly correlated with both time- and event-based PM for controls (strong relationships). Note-taking was also significantly strongly correlated to time-based PM for controls. Variables entered into the time-based PM regression analyses for controls included age and note-taking. Age was entered into the regression analysis for event-based PM for controls.

\section{Predictors of PM Performance for Individuals with Stroke}

Two multiple regression analyses were conducted to estimate the proportion of variance in time- and event-based PM for individuals with stroke that could be accounted for by the 
Table 4. Correlational analyses between time- and event-based PM on the CAMPROMPT and potential predictor variables for individuals with stroke and controls

\begin{tabular}{|c|c|c|c|c|}
\hline & \multicolumn{2}{|c|}{ Individuals with Stroke $(n=28)$} & \multicolumn{2}{|c|}{ Controls $(n=27)$} \\
\hline & Time-based PM & Event-based PM & Time-based PM & Event-based PM \\
\hline \multicolumn{5}{|l|}{ Demographic } \\
\hline Age & -.262 & $-.400 *$ & $-.521 * *$ & $-.561 * *$ \\
\hline \multicolumn{5}{|l|}{ Cognitive factors } \\
\hline TMT & $-.562 * *$ & $-.527 * *$ & -.150 & -.147 \\
\hline HVLT-R total recall & $.605^{* *}$ & $.522 * *$ & .167 & .114 \\
\hline HVLT-R retention & $.572 * *$ & $.590 * *$ & -.064 & .059 \\
\hline MoCA total & $.492 *$ & $.694 * *$ & .299 & .231 \\
\hline \multicolumn{5}{|l|}{ Metacognitive variables } \\
\hline CAMPROMPT note-taking & $.763 * *$ & $.486^{* *}$ & $.531 * *$ & -.063 \\
\hline BAPM total & $.482 * *$ & $.523 * *$ & -.186 & -.145 \\
\hline PRMQ PM & $.578 * *$ & $.479 * *$ & -.157 & -.239 \\
\hline
\end{tabular}

Note. $* p<.05, * * p<.01 . \mathrm{PM}=$ prospective memory; TMT $=$ Trail Making Test; HVLT-R $=$ Hopkins Verbal Learning TestRevised; MoCA = Montreal Cognitive Assessment; CAMPROMPT $=$ Cambridge Prospective Memory Test; BAPM $=$ Brief Assessment of PM; PRMQ = Prospective and Retrospective Memory Questionnaire.

Table 5. Unstandardised $(B)$ and standardised $(\beta)$ regression coefficients, and squared semi-partial correlations $\left(s r^{2}\right)$ for each predictor variable of the multiple regression analysis predicting CAMPROMPT time- and event-based PM for individuals with stroke

\begin{tabular}{|c|c|c|c|c|c|c|c|c|c|c|}
\hline \multirow[b]{3}{*}{ Variable } & \multicolumn{5}{|c|}{ Time-based PM } & \multicolumn{5}{|c|}{ Event-based PM } \\
\hline & \multirow[b]{2}{*}{$B$} & \multicolumn{2}{|c|}{$95 \% \mathrm{CI}$} & \multirow[b]{2}{*}{$\beta$} & \multirow[b]{2}{*}{$s r^{2}$} & \multirow[b]{2}{*}{$B$} & \multicolumn{2}{|c|}{$95 \% \mathrm{CI}$} & \multirow[b]{2}{*}{$\beta$} & \multirow[b]{2}{*}{$s r^{2}$} \\
\hline & & Lower bound & Upper bound & & & & Lower bound & Upper bound & & \\
\hline \multicolumn{11}{|l|}{ Demographic } \\
\hline Age & - & - & - & - & - & -.122 & -.206 & -.037 & -.387 & $.127 * *$ \\
\hline \multicolumn{11}{|l|}{ Cognitive } \\
\hline TMT & -.027 & -.069 & .015 & -.280 & .030 & -.022 & -.054 & .011 & -.270 & .028 \\
\hline HVLT-R total recall & -.103 & -.548 & .341 & -.113 & .004 & -.356 & -.698 & -.013 & -.468 & $.066^{*}$ \\
\hline HVLT-R retention & .020 & -.043 & .084 & .122 & .007 & .067 & .016 & .119 & .489 & $.104 *$ \\
\hline $\begin{array}{l}\text { MoCA total } \\
\text { Metacognitive }\end{array}$ & -.139 & -.838 & .559 & -.077 & .003 & .839 & .306 & 1.372 & .560 & $.151 * *$ \\
\hline $\begin{array}{l}\text { CAMPROMPT } \\
\text { note-taking }\end{array}$ & 6.287 & 2.991 & 9.583 & .612 & $.262 * *$ & 1.406 & -1.114 & 3.926 & .165 & .019 \\
\hline BAPM total & -.193 & -4.991 & 4.605 & -.017 & .000 & -.513 & -4.302 & 3.276 & -.054 & .001 \\
\hline PRMQ PM & .213 & -.107 & .533 & .290 & .032 & -.019 & -.264 & .226 & -.031 & .000 \\
\hline
\end{tabular}

Note. $* p<.05, * * p<01$. CAMPROMPT $=$ Cambridge Prospective Memory Test $\mathrm{PM}=$ prospective memory $\mathrm{CI}=$ confidence interval; $\mathrm{TMT}=\mathrm{Trail}$ Making Test; HVLT-R = Hopkins Verbal Learning Test-Revised; MoCA = Montreal Cognitive Assessment; BAPM = Brief Assessment of Prospective Memory; $\mathrm{PRMQ}=$ Prospective and Retrospective Memory Questionnaire.

demographic, cognitive, and metacognitive variables (Table 5). In the first multiple regression, in combination, the predictors accounted for a significant $70.7 \%$ of the variability in time-based $\mathrm{PM}, R^{2}=.707, F(7,18)=6.19, p<.001, f^{2}=2.41$ (large effect size) for individuals with stroke. Only note-taking $(p=.001)$ significantly contributed to the prediction of CAMPROMPT time-based scores for individuals with stroke. In the second regression, in combination, the predictors accounted for a significant $76.7 \%$ of the variability in event-based PM for individuals with stroke, $R^{2}=.767, F(8,17)=6.99, p<.001, f^{2}=3.29$ (large effect size). Age $(p=.007)$, total recall $(p=.043)$, retention $(p=.014)$, and global cognitive function $(p=.004)$ significantly contributed to the prediction of CAMPROMPT event-based scores for individuals with stroke.

\section{Predictors of PM Performance for Controls}

Two multiple regression analyses were conducted to estimate the proportion of variance in time- and event-based PM for controls that could be accounted for by the demographic and metacognitive variables (Table 6). For the first multiple regression, in combination, the predictors accounted for a 
Table 6. Unstandardised $(B)$ and standardised $(\beta)$ regression coefficients, and squared semi-partial correlations $\left(s r^{2}\right)$ for each predictor variable of the multiple regression analysis predicting CAMPROMPT time- and event-based PM for controls

\begin{tabular}{|c|c|c|c|c|c|c|c|c|c|c|}
\hline \multirow[b]{3}{*}{ Variable } & \multicolumn{5}{|c|}{ Time-based PM } & \multicolumn{5}{|c|}{ Event-based PM } \\
\hline & \multirow[b]{2}{*}{$B$} & \multicolumn{2}{|c|}{$95 \% \mathrm{CI}$} & \multirow[b]{2}{*}{$\beta$} & \multirow[b]{2}{*}{$s r^{2}$} & \multirow[b]{2}{*}{$B$} & \multicolumn{2}{|c|}{$95 \% \mathrm{CI}$} & \multirow[b]{2}{*}{$\beta$} & \multirow[b]{2}{*}{$s r^{2}$} \\
\hline & & $\begin{array}{l}\text { Lower } \\
\text { bound }\end{array}$ & $\begin{array}{l}\text { Upper } \\
\text { bound }\end{array}$ & & & & $\begin{array}{l}\text { Lower } \\
\text { bound }\end{array}$ & $\begin{array}{l}\text { Upper } \\
\text { bound }\end{array}$ & & \\
\hline \multicolumn{11}{|l|}{ Demographic } \\
\hline Age & -.143 & -.255 & -.031 & -.414 & $.161 *$ & -.185 & -.297 & -.073 & -.561 & $.315^{* *}$ \\
\hline \multicolumn{11}{|l|}{ Metacognitive } \\
\hline CAMPROMPT note-taking & 3.716 & .893 & 6.539 & .428 & $.171^{*}$ & - & - & - & - & - \\
\hline
\end{tabular}

Note. ${ }^{*} p<.05, * * p<.01$. CAMPROMPT $=$ Cambridge Prospective Memory Test; $\mathrm{PM}=$ prospective memory; $\mathrm{CI}=$ confidence interval.

significant $44.3 \%$ of the variability in time-based PM for controls, $R^{2}=.443, F(2,24)=9.55, p=.001, f^{2}=.80$ (large effect size). Age $(p=.015)$ and note-taking $(p=.012)$ significantly contributed to the prediction of CAMPROMPT time-based scores for controls. For the second regression, in combination, the predictors accounted for a significant $31.5 \%$ of the variability in event-based PM for controls, $R^{2}=.315, F(1,25)=11.51, p=.002, f^{2}=.46$ (medium effect size). Age $(p=.002)$ was the only significant predictor of CAMPROMPT event-based scores for controls.

\section{DISCUSSION}

The current study aimed to compare the PM performance of individuals with stroke to controls to clarify the extent of PM impairment after stroke. The hypothesis was supported as individuals with stroke performed significantly poorer on the CAMPROMPT total score as well as the time- and event-based subscores compared to controls. These results provide evidence that PM impairment exists after stroke. When time- and event-based PM was compared, significant differences were found, where performance was significantly worse on time- compared to event-based PM. No significant interaction between Group and Task Type was found, indicating that individuals with stroke found the event- and timebased PM tasks to be of similar difficulty. Because there was no significant interaction between Group and Task Type, the reason for PM impairment for individuals with stroke is not likely to be due to the cognitive demand associated with the self-initiated retrieval needed for completion of the time-based PM task.

The current findings are in line with previous research (Barr, 2011; Man, Yip, et al., 2015) that reported that individuals with stroke performed poorer on all three scores of the CAMPROMPT compared to controls. When compared to normative means, $39.2 \%$ of the current stroke sample showed some level of PM impairment (impaired, borderline, poor), slightly higher than previous research reporting 33.3\% (Mitrovic et al., 2016) and in line with previous findings (Miller \& Radford, 2014). The current findings slightly differ to one previous study which found that individuals with stroke performed poorer than controls on time- but not event-based PM (Kim et al., 2009), possibly due to the smaller sample size of the previous study or different PM measures used. Nonetheless, the findings of the current study indicate that PM impairment does exist after stroke, but not necessarily for the entire population. This variation could be due to the location or severity of an individual's stroke (e.g., individuals with stroke in posterior regions would not be expected to show PM deficits as activations in the prefrontal lobe are common during PM tasks; Burgess et al., 2011), deficits in other cognitive domains (i.e., attention, EF, RM, etc.), as well as other factors previously shown to impact PM (i.e., monitoring ability, cue focality, task difficulty, etc.).

\section{Predictors}

An additional aim of the current study was to clarify the nature of PM impairment after stroke by exploring predictors of PM. It was hypothesised that demographic, cognitive, and metacognitive factors would significantly predict PM performance post-stroke. This hypothesis was supported; however, not all variables significantly predicted PM performance.

\section{Demographic factors}

Age significantly predicted event-based PM for both individuals with stroke and controls with older participants having poorer PM performance. This finding supports previous research (Kvavilashvili et al., 2009; Park et al., 1997) which also found that age predicts event-based PM. Age predicted time-based PM for controls which is in line with previous research (Einstein et al., 1995; Kvavilashvili et al., 2009; Park et al., 1997) but no relationship was found for individuals with stroke. Individual differences in EF could be related to PM performance, particularly in old age (Martin et al., 2003), with higher levels of PM performance in older adults being dependent on stronger EF. As stroke populations in general are older (over 65 years of age), including the one used in the current study, it is reasonable to assume that age may play a role in PM, if not directly, then through age-related decline in cognitive functioning. This seems to be the case for the current sample as age and multiple cognitive variables were found to predict event-based PM after stroke. 


\section{Cognitive factors}

All cognitive factors were significantly associated with both event- and time-based PM for individuals with stroke, with higher scores indicating better PM performance; however, none were found to significantly predict time-based PM. Total recall, retention, and global cognitive function significantly predicted event-based PM after stroke. Previous findings (Kant et al., 2014) suggest that only RM is predictive of event-based PM, whereas, processing speed, attention/EFs, and RM significantly predict time-based PM after stroke. Therefore, the current findings did not support previous research that suggests cognitive processes are more predictive of time- than event-based PM (Fleming et al., 2008; Groot et al., 2002; Martin et al., 2003). Rather they supported previous literature that suggests cognitive factors are also predictive of event-based PM (Schnitzspahn et al., 2013; Zuber et al., 2016). Perhaps, this result can be accounted for by note-taking, which has not been directly assessed before in a stroke population, explaining the variance.

\section{Metacognitive factors}

Strategy use (note-taking) was associated with time-based PM and significantly predicted time-based PM performance for both individuals with stroke and controls, with note-taking significantly improving performance. The same pattern of results has been found previously in a TBI sample (Fleming et al., 2008). As a predictor of time-based PM, note-taking may be related to an individual's monitoring strategy because time-based tasks require more monitoring from the individual compared to event-based tasks. It is assumed that those who took notes would refer to them while completing the task. This could be considered a type of monitoring (instead of clock-checking, they are checking notes) and may mean that those who checked their notes more often may have also checked the time more often, resulting in higher time-based PM performance. However, this is speculative as time monitoring was not measured in the current study but has been found to positively correlate with time-based PM performance in previous stroke research (Kant et al., 2014).

Self-reported PM on the PRMQ and BAPM was significantly positively correlated with both time- and event-based PM for individuals with stroke, however, did not predict PM performance. This relationship seems counterintuitive. The pattern of results suggests that as individuals self-reported more PM impairment, their PM performance increased. One would assume that more self-reported PM failures would correlate with poorer CAMPROMPT performance; however, the current findings suggest the opposite. These findings may indicate a lack of self-awareness for some individuals with stroke into their own PM abilities, which has been suggested by previous research (Brooks et al., 2004; Kim et al., 2009; Man, Yip, et al., 2015). Therefore, while valuable information can be gained into an individual's understanding of their own PM abilities, self-reported PM may not be a valid measure of actual PM performance. Given that self-reported questionnaires do not actually measure PM performance
(Uttl \& Kibreab, 2011), as evidenced by the discrepancy between the self-report and CAMPROMPT results in the current study, it is important that research examining PM using self-reported methods be interpreted with caution and limitations taken into consideration.

\section{Implications}

The findings of the current study highlight that PM impairment does exist after stroke and suggests possible reasons for these impairments, helping to clarify both the extent and nature of PM impairment after stroke. A different pattern of results was found suggesting that stroke has a unique effect on PM. For time-based PM, a metacognitive factor predicted PM for both controls and individuals with stroke, whereas the demographic variable of age only predicted PM for controls. Age was predictive of event-based PM for controls and individuals with stroke. Additionally, cognitive factors only predicted event-based PM for individuals with stroke. The current study has built on the previous research by recruiting a larger sample size than most, using standardised measures of PM, and by exploring possible predictors of PM after stroke, notably note-taking in the prediction of time-based PM. However, further research is needed to corroborate these findings and additional research should be conducted to determine indicators of PM impairment after stroke (e.g., type of stroke, location of impairment). If individuals are showing certain indicators, it would allow clinicians to assess and provide rehabilitation for PM quickly, instead of waiting for PM problems to arise. Additionally, individuals with stroke need to be educated on the consequences of such impairments to prioritise PM in their rehabilitation period.

\section{Limitations}

A larger sample would allow for more predictor variables, like stroke characteristics (e.g., time post-stroke, stroke type/location) to be included in analyses. Additionally, the CAMPROMPT does not allow for the measurement of time monitoring, which means that we could not test this as a predictor of PM post-stroke. It is suggested that future research recruit more participants and either record the number of clock-checks a participant makes while completing the CAMPROMPT or include another PM task which allows for the measurement of monitoring so that its impact on PM can be assessed.

While limitations exist in the current research, it has helped to confirm and clarify the findings of the previous literature (Barr, 2011; Man, Chan, et al., 2015; Miller \& Radford, 2014; Mitrovic et al., 2016), in that when using a standardised measure of PM, individuals with stroke show impairment in PM ability when compared to either controls or normative means. These PM impairments may be due to a number of factors, including age, strategy use, and cognitive abilities. Future research is needed to examine strategy use in stroke populations in order to inform the development of appropriate PM interventions. 


\section{ACKNOWLEDGEMENTS}

This work was supported by a Griffith University Postgraduate Scholarship.

\section{CONFLICT OF INTEREST}

None.

\section{REFERENCES}

Al Banna, M., Redha, N.A., Abdulla, F., Nair, B., \& Donnellan, C. (2016). Metacognitive function poststroke: A review of definition and assessment. Journal of Neurology Neurosurgery and Psychiatry, 87(2), 161-166. doi: 10.1136/jnnp-2015-310305

Andrews, G., Halford, G.S., Chappell, M., Maujean, A., \& Shum, D. (2014). Planning following stroke: A relational complexity approach using the tower of London. Frontiers in Human Neuroscience, 8(1032), 1-14. doi: 10.3389/fnhum.2014.01032

Andrews, G., Halford, G.S., Shum, D.H., Maujean, A., Chappell, M., \& Birney, D.P. (2014). Verbal learning and memory following stroke. Brain Injury, 28(4), 442-447. doi: 10.3109/02699052. 2014.888758

Australian Institute of Health and Welfare [AIHW]. (2016). Australia's health 2016. (Australia's Health Series No. 15. Cat. No. AUS 199). Canberra: AIHW. Retrieved from https://www. aihw.gov.au/reports/australias-health/australias-health-2016/ contents/summary

Barr, A.C. (2011). Prospective memory functioning after stroke: A research portfolio. (Doctoral thesis, University of Edinburgh, Scotland). Retrieved from https://www.era.lib.ed.ac.uk/handle/ 1842/6049.

Benedict, R.H.B., Schretlen, D., Groninger, L., \& Brandt, J. (1998). Hopkins verbal learning test - revised: Normative data and analysis of inter-form and test-retest reliability. The Clinical Neuropsychologist, 12(1), 43-55. doi: 10.1076/clin.12.1.43.1726

Brooks, B.M., Rose, F.D., Potter, J., Jayawardena, S., \& Morling, A. (2004). Assessing stroke patients' prospective memory using virtual reality. Brain Injury, 18(4), 391-401. doi: 10.1080/ 02699050310001619855

Burgess, P.W., Gonen-Yaacovi, G., \& Volle, E. (2011). Functional neuroimaging studies of prospective memory: What have we learnt so far? Neuropsychologia, 49(8), 2246-2257. doi: 10.1016/ j.neuropsychologia.2011.02.014

Crawford, J., Henry, J.D., Ward, A.L., \& Blake, J. (2006). The prospective and retrospective memory questionnaire (PRMQ): Latent structure, normative data and discrepancy analysis for proxyratings. British Journal of Clinical Psychology, 45(1), 83-104. doi: 10.1348/014466505X28748

Crawford, J., Smith, G., Maylor, E., Della Sala, S., \& Logie, R. (2003). The prospective and retrospective memory questionnaire (PRMQ): Normative data and latent structure in a large nonclinical sample. Memory, 11(3), 261-275. doi: 10.1080/ 09658210244000027

d'Ydewalle, G., Luwel, K., \& Brunfaut, E. (1999). The importance of on-going concurrent activities as a function of age in time-and event-based prospective memory. European Journal of Cognitive Psychology, 11(2), 219-237. doi: 10.1080/713752309

Einstein, G.O. \& McDaniel, M.A. (1990). Normal aging and prospective memory. Journal of Experimental Psychology: Learning, Memory, and Cognition, 16(4), 717-726. doi: 10.1037/02787393.16.4.717
Einstein, G.O., McDaniel, M.A., Richardson, S.L., Guynn, M.J., \& Cunfer, A.R. (1995). Aging and prospective memory: Examining the influences of self-initiated retrieval processes. Journal of Experimental Psychology: Learning, Memory, and Cognition, 21(4), 996-1007. doi: 10.1037/0278-7393.21.4.996

Fleming, J., Riley, L., Gill, H., Gullo, M.J., Strong, J., \& Shum, D. (2008). Predictors of prospective memory in adults with traumatic brain injury. Journal of the International Neuropsychological Society, 14(5), 823-831. doi: 10.1017/S1355617708080971

Groot, Y.C.T., Wilson, B.A., Evans, J., \& Watson, P. (2002). Prospective memory functioning in people with and without brain injury. Journal of the International Neuropsychological Society, 8(5), 645-654. doi: 10.1017/S1355617702801321

Henry, J.D. \& Crawford, J.R. (2005). The short-form version of the depression anxiety stress scales (DASS-21): Construct validity and normative data in a large non-clinical sample. British Journal of Clinical Psychology, 44(2), 227-239. doi: 10.1348/ $014466505 X 29657$

Henry, J.D., MacLeod, M.S., Phillips, L.H., \& Crawford, J.R. (2004). A meta-analytic review of prospective memory and aging. Psychology and Aging, 19(1), 27-39. doi: 10.1037/0882-7974. 19.1.27

Hogan, C., Fleming, J., Cornwell, P., \& Shum, D. (2016). Prospective memory after stroke: A scoping review. Brain Impairment, 17(2), 123-142. doi: 10.1017/BrImp.2016.12

IBM Corporation. (2017). IBM SPSS Statistics (Version 25) [Computer Software]. New York: IBM Corporation.

Kant, N., van den Berg, E., van Zandvoort, M.J.E., Frijns, C.J.M., Kappelle, L.J., \& Postma, A. (2014). Functional correlates of prospective memory in stroke. Neuropsychologia, 60(1), 77-83. doi: 10.1016/j.neuropsychologia.2014.05.015

Kim, H.J., Craik, F., Luo, L., \& Ween, J.E. (2009). Impairments in prospective and retrospective memory following stroke. Neurocase, 15(2), 145-156. doi: 10.1080/13554790802709039

Knight, R.G., Harnett, M., \& Titov, N. (2005). The effects of traumatic brain injury on the predicted and actual performance of a test of prospective remembering. Brain Injury, 19(1), 19-27. doi: 10.1080/02699050410001720022

Kvavilashvili, L. \& Ellis, J. (1996). Varieties of intention: Some distinctions and classifications. In M. Brandimonte, G.O. Einstein, \& M.A. McDaniel (Eds.), Prospective memory: Theory and applications (pp. 23-51). New Jersey: Lawrence Erlbaum Associates, Inc.

Kvavilashvili, L., Kornbrot, D.E., Mash, V., Cockburn, J., \& Milne, A. (2009). Differential effects of age on prospective and retrospective memory tasks in young, young-old, and old-old adults. Memory, 17(2), 180-196. doi: 10.1080/09658210802194366

Leung, D.P.K. \& Liu, K.P.Y. (2011). Review of self-awareness and its clinical application in stroke rehabilitation. International Journal of Rehabilitation Research, 34(3), 187-195. doi: 10.1097/MRR.0b013e3283487f31

Livingston, J.A. (2003). Metacognition: An Overview. Retrieved from https://files.eric.ed.gov/fulltext/ED474273.pdf

Man, D.W.K., Chan, M.K.L., \& Yip, C.C.K. (2015). Validation of the Cambridge prospective memory test (Hong Kong Chinese version) for people with stroke. Neuropsychological Rehabilitation, 25(6), 895-912. doi: 10.1080/09602011.2014.997253

Man, D.W.K., Fleming, J., Hohaus, L., \& Shum, D. (2011). Development of the brief assessment of prospective memory (BAPM) for use with traumatic brain injury populations. Neuropsychological Rehabilitation, 21(6), 884-898. doi: 10.1080/09602011.2011.627270. 
Man, D., Yip, C., Lee, G., Fleming, J., \& Shum, D. (2015). Self-report prospective memory problems in people with stroke. Brain Injury, 29(3), 329-335. doi: 10.3109/02699052.2014.974672.

Martin, M., Kliegel, M., \& McDaniel, M.A. (2003). The involvement of executive functions in prospective memory performance of adults. International Journal of Psychology, 38(4), 195-206. doi: 10.1080/00207590244000205

McDaniel, M.A. \& Einstein, G.O. (2000). Strategic and automatic processes in prospective memory retrieval: A multiprocess framework. Applied Cognitive Psychology, 14(7), S127-S144. doi: 10.1002/acp.775

Miller, L.A. \& Radford, K. (2014). Testing the effectiveness of group-based memory rehabilitation in chronic stroke patients. Neuropsychological Rehabilitation, 24(5), 721-737. doi: 10.1080/09602011.2014.894479

Mitrovic, A., Mathews, M., Ohlsson, S., Holland, J., \& McKinlay, A. (2016). Computer-based post-stroke rehabilitation of prospective memory. Journal of Applied Research in Memory and Cognition, 5(1), 204-214. doi: 10.1016/j.jarmac.2016.03.006

Nasreddine, Z.S., Phillips, N.A., Bédirian, V., Charbonneau, S., Whitehead, V., Collin, I., ... Chertkow, H. (2005). The Montreal cognitive assessment, MoCA: A brief screening tool for mild cognitive impairment. Journal of the American Geriatrics Society, 53(4), 695-699. doi: 10.1111/j.1532-5415.2005.53221.x

Niedźwieńska, A. \& Barzykowski, K. (2012). The age prospective memory paradox within the same sample in time-based and eventbased tasks. Aging, Neuropsychology, and Cognition, 19(1-2), 58-83. doi: 10.1080/13825585.2011.628374

Nouri, F.M. \& Lincoln, N.B. (1987). An extended activities of daily living scale for stroke patients. Clinical Rehabilitation, 1(4), 301-305. doi: 10.1177/026921558700100409

Otani, H., Landau, J.D., Libkuman, T.M., Louis, J.P.S., Kazen, J.K., \& Throne, G.W. (1997). Prospective memory and divided attention. Memory, 5(3), 343-360. doi: 10.1080/741941393

Park, D.C., Hertzog, C., Kidder, D.P., Morrell, R.W., \& Mayhorn, C.B. (1997). Effect of age on event-based and time-based prospective memory. Psychology and Aging, 12(2), 314-327. doi: 10.1037/0882-7974.12.2.314

Rankin, J. (1957). Cerebral vascular accidents in patients over the age of 60: II. prognosis. Scottish Medical Journal, 2(5), 200-215. doi: 10.1177/003693305700200504
Rendell, P.G. \& Craik, F.I. (2000). Virtual week and actual week: Age-related differences in prospective memory. Applied Cognitive Psychology, 14(7), S43-S62. doi: 10.1002/acp.770

Schnitzspahn, K.M., Stahl, C., Zeintl, M., Kaller, C.P., \& Kliegel, M. (2013). The role of shifting, updating, and inhibition in prospective memory performance in young and older adults. Developmental Psychology, 49(8), 1544-1553. doi: 10.1037/ a0030579

Shum, D., Fleming, J., \& Neulinger, K. (2002). Prospective memory and traumatic brain injury: A review. Brain Impairment, 3(1), 1-16. doi: 10.1375/brim.3.1.1

Shum, D., Levin, H., \& Chan, R.C.K. (2011). Prospective memory in patients with closed head injury: A review. Neuropsychologia, 49(8), 2156-2165. doi: 10.1016/j.neuropsychologia.2011.02.006

Smith, G., Del Sala, S., Logie, R.H., \& Maylor, E.A. (2000). Prospective and retrospective memory in normal ageing and dementia: A questionnaire study. Memory, 8(5), 311-321. doi: 10.1080/09658210050117735

Smith, R.E. (2003). The cost of remembering to remember in eventbased prospective memory: Investigating the capacity demands of delayed intention performance. Journal of Experimental Psychology: Learning, Memory, and Cognition, 29(3), 347-361. doi: 10.1037/0278-7393.29.3.347

Strauss, E., Sherman, E.M., \& Spreen, O. (2006). A compendium of neuropsychological tests: Administration, norms, and commentary. New York: Oxford University Press.

Tombaugh, T.N. (2004). Trail making test A and B: Normative data stratified by age and education. Archives of Clinical Neuropsychology, 19(2), 203-214. doi: 10.1016/S08876177(03)00039-8

Uttl, B. \& Kibreab, M. (2011). Self-report measures of prospective memory are reliable but not valid. Canadian Journal of Experimental Psychology/Revue Canadienne De Psychologie Experimentale, 65(1), 57-68. doi: 10.1037/a0022843

Wilson, B., Shiel, A., Foley, J., Emslie, H., Groot, Y., Hawkins, K., \& Watson, P. (2005). Cambridge test of prospective memory (CAMPROMPT). San Antonio: Pearson Assessment.

Zuber, S., Kliegel, M., \& Ihle, A. (2016). An individual difference perspective on focal versus nonfocal prospective memory. Memory \& Cognition, 44(8), 1192-1203. doi: 10.3758/s13421016-0628-5 